\title{
Portable Child Seat Design for Motorcycle in the Front and Back Positions
}

\author{
Farid Triawan $^{1 *}$, Putri Angelica ${ }^{1,2}$, Desinta Dewi Ramadani ${ }^{1,2}$, Pusva Juliana ${ }^{1,2}$ \\ ${ }^{1}$ Department of Mechanical Engineering, Faculty of Engineering and Technology, Sampoerna University, Jakarta, \\ 12780, Indonesia \\ ${ }^{2}$ Department of Aerospace and Mechanical Engineering, The University of Arizona, Tucson, AZ, 85721, US. \\ *Email: farid.triawan@sampoernauniversity.ac.id
}

\begin{abstract}
In Indonesia, it is a common practice for people in the urban area to bring children when riding a motorcycle. This habit raises a safety issue for the children as well as the motorcycle rider. For this reason, an additional child seat that allows the child to sit safely is demanded. This study aims to produce an innovative design of an additional child seat for a motorcycle that is portable, safe, durable, easy to use, and comfortable. The seat is designed so that it can be installed at the front and back sides of the rider in the motorcycle. The proposed model is designed to have a mass of between 0.6 to 3 kilograms. It is equipped with a seatbelt and head-protection pad. To evaluate the structural strength, theoretical analyses of solid mechanics were performed under static and fatigue loading conditions. As a result, the static safety factor of the child seat design for the front position was found to be 3.67. On the other hand, the fatigue safety factor of the child seat design for the front position was found to be 2.26 , which is considered an infinite life. For the back position, the fatigue safety factor was found to be 2.36. The proposed design is expected to give a contribution to the development of innovative devices in transportation technology.
\end{abstract}

\section{Keywords}

Child seat; Motorcycle; Portable; Safety; Front and back

\section{Introduction}

In Indonesia, the number of motorcycles has increased significantly in the last ten years [1]. The number of motorcycle riders reached 130 million in 2019 [2]. In the same year, the total number of people who died caused by road accidents was reported to be around 25671, where the first most case were motorcycle accidents followed by truck and bus accidents [3], [4]. It is a common practice that motorcycle riders often carry small children using a child seat while riding [5]. Not only in Indonesia, but most motorcycle riders in southeast Asia (like Malaysia and Thailand) also often bring their children. They are mostly seated in front of the rider or behind the rider [6], [7]. This may bring serious safety issues [8].

Bringing the children to riding a motorcycle increases the injury risk when the accident happens because a child has a smaller body and less developed bones compared to the adult [9]. It also means that the rider might be disturbed by the child, which can cause a fatal accident. When the rider is driving alone, they tend to put their child in front of them without any additional safety device. Some of them put the bamboo or wooden chair as the extra seat on the front side of the motorcycle, which lacks safety since it is not fixed anywhere, so there is a strong possibility of the chair falling easily, shaking, and moving unstable. These issues can result in uncomfortableness for both the rider and child or even the worst possibility it can cause an accident. To overcome these problems, people should use a safety seat that is safe for children.

The idea of making a child safety seat that can be placed on the front and back sides of the motorcycle, is to increase the effectiveness of using a safety seat. Depending on the situation, the user can choose to use the seat on the front or back side. By using the front side, the rider can watch for the children and provide a wide space remaining on the back side. Thus, it will allow the rider to carry luggage or bring another person on the back side. However, when the rider does not bear any luggage and drives alone, they can easily take off the seat from the front frame and install it on the back side.

This research aims to design an additional child seat design in a motorcycle that can be used on the front and back sides. The seat provides more safety compared to the wooden chair, considering the materials, chair maximum height, stress analysis under static and fatigue loads. The proposed safety seat also offers a safety belt, protective pads, adjustable backrest, adjustable height on the front side, and soft materials for the chair to guarantee the child's comfort and safety. The safety issue regarding the proposed design was then discussed. 


\section{$2 \quad$ Methodology}

To obtain a high-quality child seat product, several steps of the design procedure need to be conducted. The design flow is shown in Figure 1. Note that the process can be iterated and repeated to achieve the optimum result. The design process is started by reviewing the previous child seats available in the market, followed by defining the desired specifications, and then the creation of several design candidates in the synthesis stage. The design candidates are then analyzed. Based on the analysis, the proposed design is optimized to meet the desired specifications. Finally, the proposed design is evaluated for further improvement.

There are limited works that can be found on the design of child seat for motorcycles [8]-[10]. The design that is commonly distributed in the market was quite identic for all products. Dwijayanti et al. [10] improved the safety belt mechanism designs of the child seat for a motorcycle. The design is made with a specification of the frame leg made from rattan and safety belt made from polyester. That child seat including the cushion was designed with a dimension width of $22 \mathrm{~cm}$, a backrest height of $30 \mathrm{~cm}$, and a backrest width of $26 \mathrm{~cm}$. The dimension is identical with the additional child seat already sold in the market in which the seat was intended for a child with a weight from 7 to $14 \mathrm{~kg}$. There is a safety belt that can be adjusted based on the child's body. However, the locking mechanism of child seat installation to the motorbike uses the bottom frame itself, which was made to be fitted with the design of the motorcycle front footrests. This design is good, but it is somewhat questionable whether it is safe for the children or not.

In the proposed design, the frame obtained from reference [10] was synthesized to make it simpler. The leg frame was designed to be adjustable in height. The seat cushion was bolted in the frame so that it can be easily used in the back part of the motorcycle. Figure 2 shows the improved dimension and design of the child seat frame. For the material, the frame is made of Carbon Steel AISI 1018 with a mill surface finished and density of $7.87 \mathrm{~g} / \mathrm{cc}$ [11]. The belt was made to divided by half sides then locked with the same mechanism as the car seat locking mechanism for the safety belt. Therefore, the safety belt cannot be adjusted, but it is easy to be installed. There is also an additional frame that is used as the locking mechanism when installing the child seat in the front and back sides of the motorcycle.

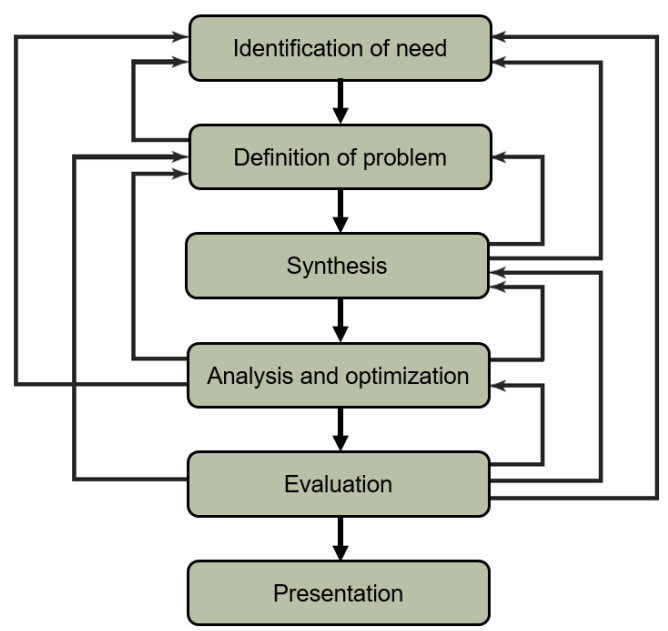

Figure 1 Design procedure [12].
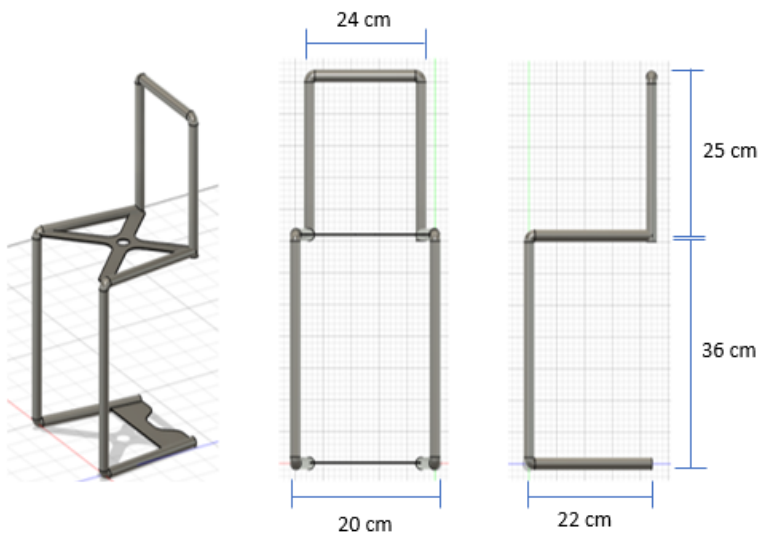

Figure 2 Improved child seat frame.

The maximum load applied in this seat were assumed for the kid with a maximum mass of $40 \mathrm{~kg}$ (weight of $392.4 \mathrm{~N}$ ), with a dynamic load range from $196.2 \mathrm{~N}(20$ $\mathrm{kg})$ to $588.6 \mathrm{~N}(60 \mathrm{~kg})$. The load applied on the backrest was assumed to be half of the load applied on the seat.

\section{Results and Discussion}

The design of the child seat has legs that only stand on the front side, and it can be folded so that the user can carry and move the child seat easily. The type of telescoping legs and the folding chair's lever was chosen to support the folding mechanism. By considering the weight of the structure and the cost, carbon steel was chosen as the primary material. Considering the type of material used, constrained space from the motorcycle, and the aesthetic value, improvements of the final design are generated. 


\subsection{General specification}

The material for the mainframe was made of Carbon Steel AISI 1018 and the supported link for the backposition was made of Steel AISI 1045. The chair seat and backrest cushion were made of HD36 foam regular. The safety equipment consists of a safety belt and a protective pad. The safety belt provides safety in holding the child when there is a sudden shock. The seat belt protects the child by retaining her/him in the backrest cushion so that the head and chest area stay safe when an accident happens. The protective pad was designed in such a way to support the seat belt function to prevent injuries in a crash, especially for the head.

The child seat design can be used in the front side (see Figure 3) or the motorcycle's rear position (see Figure 4). The main leg of the child seat can be removed and replaced by a pair of supporting parts. The main leg stands only on the front side, and it can be folded so that the user can easily carry and move the child seat.
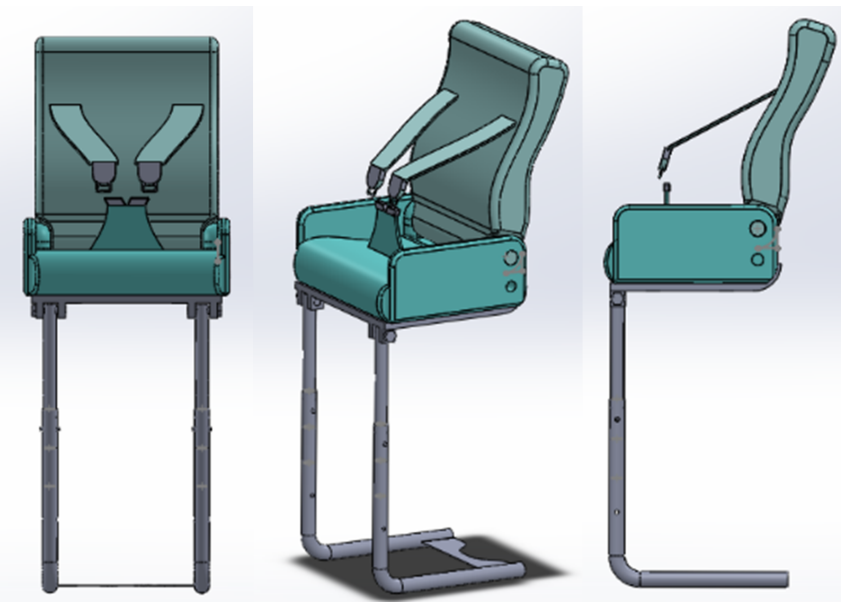

Figure 3 Front seat design.

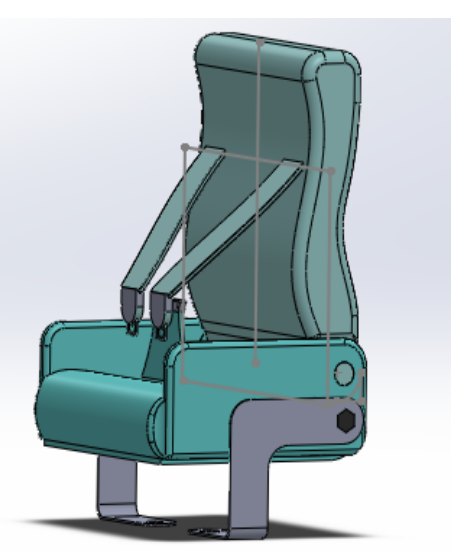

Figure 4 Back seat design.

\subsection{Mechanical strength calculation for the front position}

To assure the child seat was safe during service, a mechanical strength calculation was conducted. Note that all load from child weight has to be held by the mainframe of the child seat. Thus, the mechanical calculation required the mechanical properties of the mainframe. It has been determined from the design process that the mainframe of the child seat is made from Carbon Steel AISI 1018. The mechanical properties of the steel are summarized in Table 1.

Table 1 Mechanical properties of carbon steel AISI 1018.

\begin{tabular}{lc}
\hline \multicolumn{1}{c}{ Mechanical Properties } & Value \\
\hline Tensile Strength, Ultimate & $440 \mathrm{MPa}$ \\
Tensile Strength, Yield & $370 \mathrm{MPa}$ \\
Modulus of Elasticity (Typical for steel) & $205 \mathrm{GPa}$ \\
\hline
\end{tabular}

To perform static and fatigue analysis, a free body child seat diagram was created. Figure 5 shows the free body diagram of the child seat. Child seat is assumed to only be placed on the "ground" of a motor. If the child sits down and applies pressure to the backseat, a horizontally directed force is generated. So, it takes a pedestal to withstand the horizontal force. $W_{x}$ represents the horizontal force and $W_{y}$ indicates the vertical force that exists when the child sits on the child seat.

Figure 6 shows the reaction forces acting on the backseat of the chair. Where $h$ indicates the height of the backrest, $B_{x}$ indicates the horizontal force acting at point $\mathrm{B}, B_{y}$ indicates the vertical force acting at point $\mathrm{B}$, and $M_{B}$ indicates the bending moment at point B.

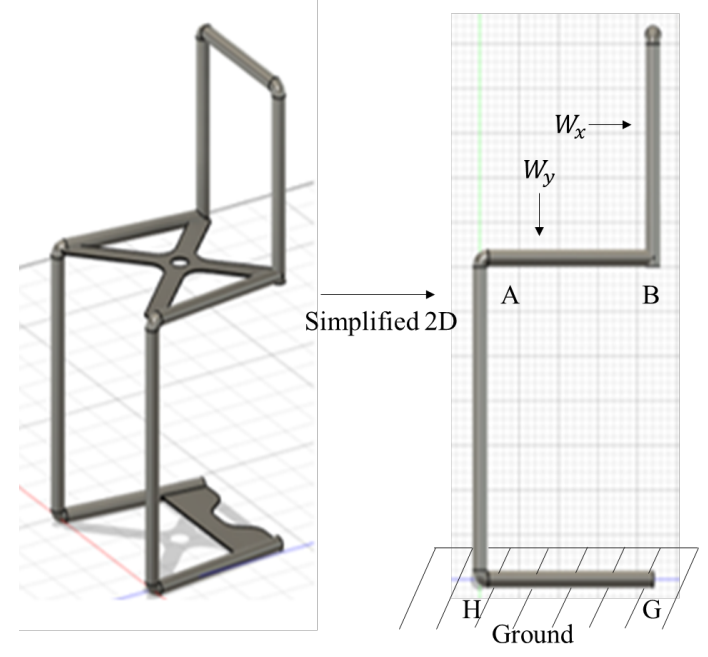

Figure 5 Free body diagram of the child seat. 


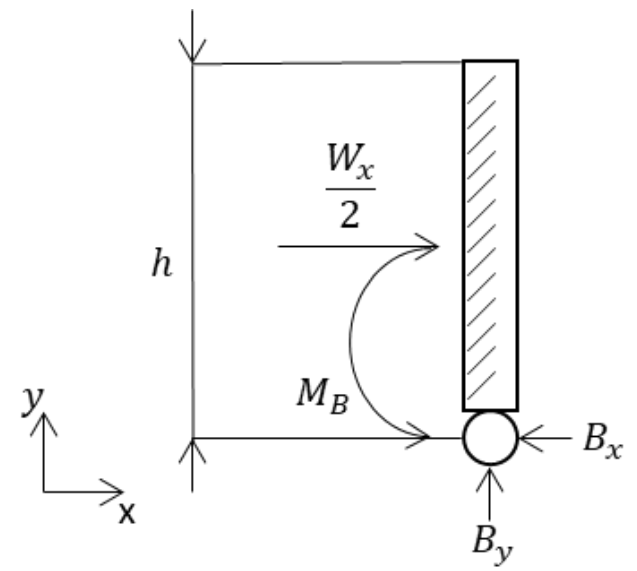

Figure 6 The force acting at point B.

To find out the values of $B_{x}, B_{y}$, and $M_{B}$, analysis of the equilibrium of the forces at the backseat section was performed. The values of $B_{x}, B_{y}$, and $M_{B}$ are obtained as can be seen below,

$\sum F_{x}=0$

$B_{x}=\frac{W_{x}}{2}$

$\sum F_{y}=0$

$B_{y}=0$

$\sum M_{B}=0$

$M_{B}=\frac{1}{4} W_{x} h$

Figure 7 shows the reaction forces acting on the chair seat frame. Where $A_{x}$ shows the horizontal forces acting at point A, $A_{y}$ shows the vertical forces acting at point $\mathrm{A}, M_{A}$ shows the bending moment at point $\mathrm{A}$, and $l$ shows the width of the child seat.

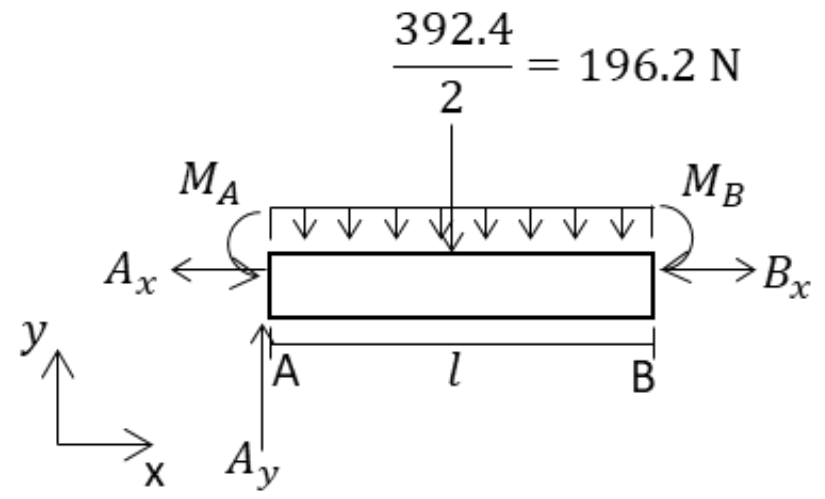

Figure 7 The reaction forces on the chair seat frame.

By performing a similar force analysis as on the backseat section, the values of $A_{x}, A_{y}$, and $M_{A}$ are obtained as can be seen below,

$\sum F_{x}=0$

$A_{x}=98.1 \mathrm{~N}$

$\sum F_{y}=0$

$A_{y}=196.2 \mathrm{~N}$

$\sum M_{A}=0$

$M_{A}-M_{B}-196.2 \frac{l}{2}=0$

$M_{A}=25.85 \mathrm{Nm}$

Figure 8 shows the internal forces inside member AB. Where $M$ represents the bending moment, $N$ represents normal force, $v$ represents shear force inside the member $\mathrm{AB}$, and $x$ represents the coordinates on the horizontal axis. 


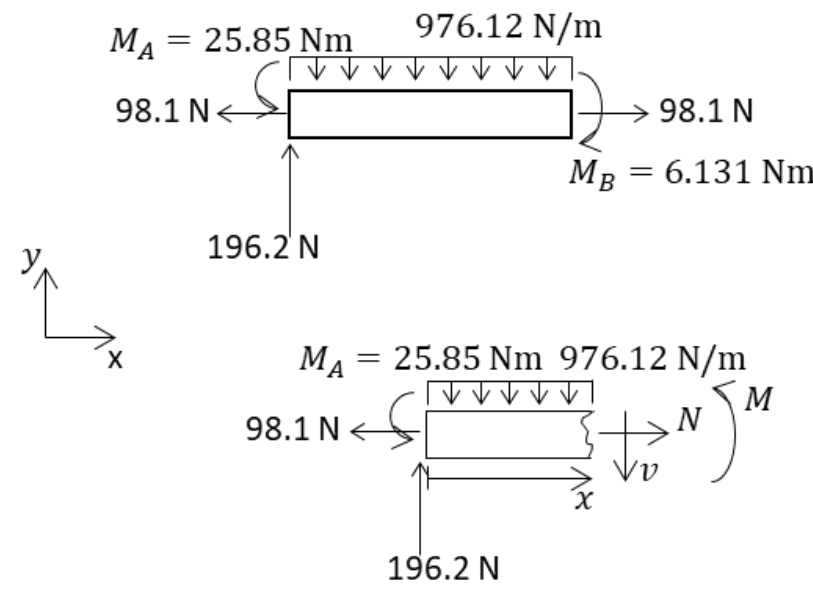

Figure 8 The internal forces inside member AB.

By analyzing the horizontal, vertical, and bending moments, the magnitudes of $N, v$, and $M$ can be found as follows.

$\sum F_{x}=0$

$N=98.1 \mathrm{~N}$

$\sum F_{y}=0$

$196.2-976.12(x)-v=0$

$v=196.2-976.12 x$

$\sum M_{A}=0$

$M_{A}-976.12 x \frac{x}{2}-v x+M=0$

$M=-25.85+196.2 x-488.06 x^{2}$

Figure 9 shows the cantilever beams of the Normal Force Diagram (NFD), Shear Force Diagram (SFD), and Bending Moment Diagram (BMD), respectively.
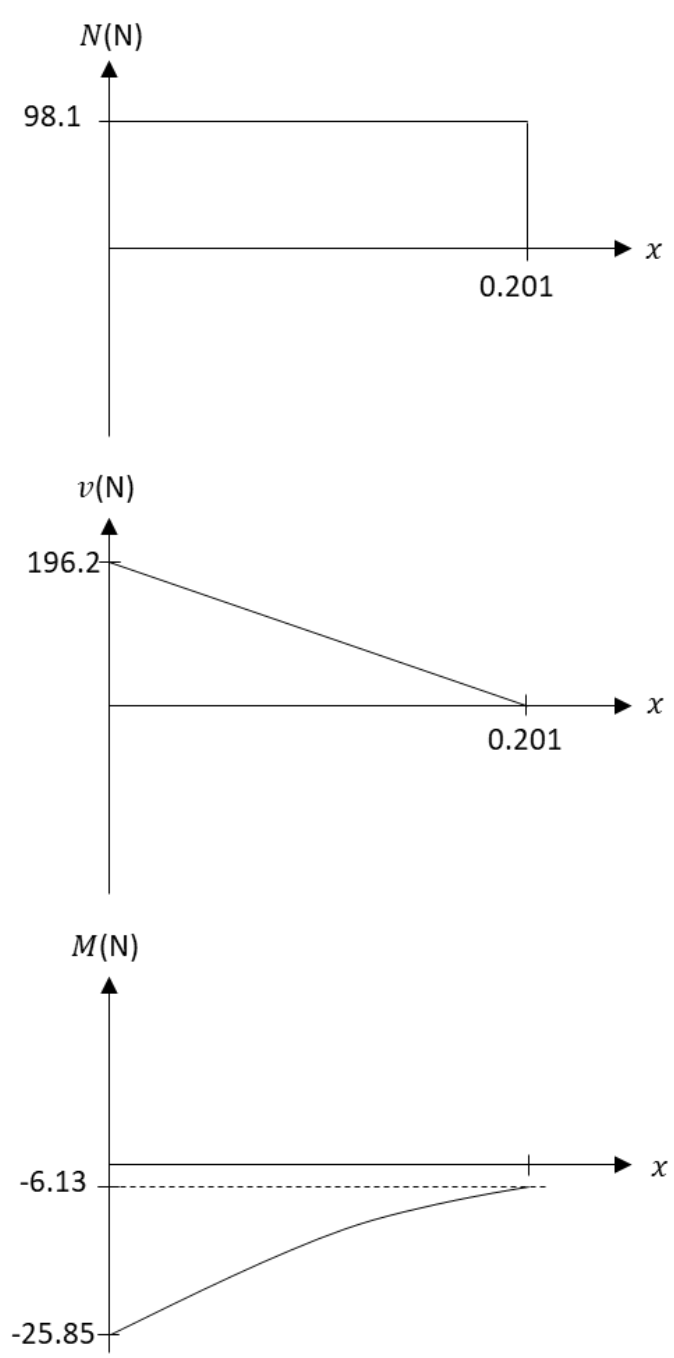

Figure 9 Cantilever beam NFD, SFD, and BMD.

The normal stress due to the normal force $\left(\sigma_{n}\right)$ is calculated as follows.

$\sigma_{n}=\frac{N}{A}=\frac{N}{\frac{1}{4} \pi\left(D_{0}^{2}-D_{i}^{2}\right)}$

Where $A$ is cross-section area, $D_{0}$ is outer diameter, and $D_{i}$ is the inner diameter of the hollow tube. The normal stress due to bending moment $\left(\sigma_{m}\right)$ is calculated as follows.

$\sigma_{m}=\frac{M c}{I}=\frac{M}{Z}$ 


$$
\begin{aligned}
z & =\frac{I}{c}=\frac{\frac{1}{4} \pi \frac{1}{16}\left(D_{0}{ }^{4}-D_{i}^{4}\right)}{R_{0}} \\
& =\frac{\frac{\pi}{64}\left(D_{0}^{4}-D_{i}^{4}\right)}{D_{0} / 2}=\frac{\pi}{32} \frac{\left(D_{0}{ }^{4}-D_{i}^{4}\right)}{D_{0}}
\end{aligned}
$$

Where $c$ is the perpendicular distance from the neutral axis to the outer tube, $I$ is moment inertia, and $z$ is the section modulus. By obtaining the normal stress values due to the normal force and bending moment, the total normal stress $\left(\sigma_{\text {Total }}\right)$ can be calculated as follows.

$\sigma_{\text {Total }}=\sigma_{m}+\sigma_{n}$

The shear stress $(\tau)$ then can be calculated as follows.

$$
\tau=\frac{V Q}{I t}
$$

$Q=\bar{y} \cdot A^{\prime}$

Where $V$ is internal shear force, $t$ is the width of the member's cross-section area, $\bar{y}$ is the distance from the neutral axis to the centroid of $A^{\prime}$, and $A^{\prime}$ is the area of the top (or bottom) portion of the member's crosssectional area.

\section{Static Analysis}

Figure 10 shows a cross-section view of the hollow tube. Analysis was carried out at Point A and Point B.

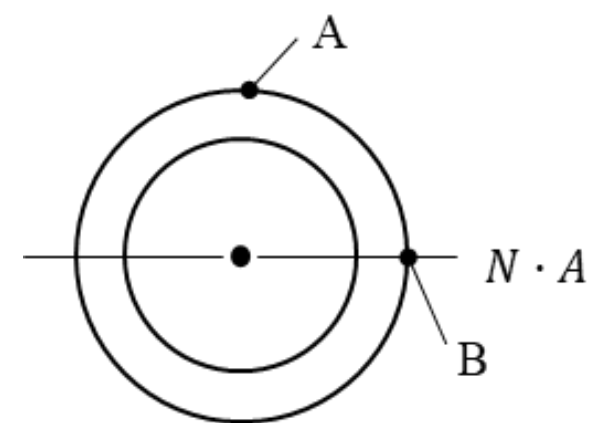

Figure 10 Cross-section view of the hollow tube; N.A: Neutral Axis.

By using Equation (11)-(16), the value of the normal stress and shear stress at Point A and B is obtained as shown in Table 2.

Table 2 The value of the normal stress and shear stress at hollow tube.

\begin{tabular}{ccc}
\hline Point & $\begin{array}{c}\text { Normal Stress } \\
(\mathbf{M P a})\end{array}$ & $\begin{array}{c}\text { Shear Stress } \\
(\mathbf{M P a})\end{array}$ \\
\hline $\mathrm{A}$ & 100.58 & 0 \\
$\mathrm{~B}$ & 1.34 & 5.34 \\
\hline
\end{tabular}

The stress values were used to calculate the static safety factor. Point A has greater static stress than Point B. Thus, the safety factor is calculated using the value of static stress at Point A as follows.

$$
n=\frac{S_{y}}{\sigma_{\text {total }}}
$$

Where $S_{y}$ is the yield strength of the material. By using the value of the tensile yield strength of carbon steel AISI 1018 as shown in Table 1, the safety factor at point A was found at 3.67.

\section{Fatigue Analysis of front position}

In conducting the fatigue analysis, some assumptions were used to calculate the Marin Modification Factor. The authors assumed that the rod was in non-rotating mode and considered the operating temperature of the product as the child seat would be used outdoor. While according to Meteorological, Climatological, and Geophysical Agency, in Indonesia, the highest temperature was recorded at the Ahmad Yani Meteorological Station, Semarang with a temperature of 36.4 degrees [13].

- Marin factor [12]

Surface condition modification factor $\left(k_{a}\right)$ is calculated as follows.

$k_{a}=a S_{u t}^{b}$

Where $S_{u t}$ is the minimum tensile strength, while $a$ and $b$ are the determined constant with $S_{u t}$ value of 440 $\mathrm{MPa}$, as shown in Table 1, and a cold-drawn surface, the value of factor $a$ is 4.51 and the exponent $b$ is 0.265 . The size factor $\left(k_{b}\right)$ for a non-rotating mode of a hollow tube is calculated as follows.

$$
\begin{aligned}
d_{e} & =0.37 d \\
k_{b} & = \begin{cases}1.24 d^{-0.107} & 2.79 \leq d \leq 51 \mathrm{~mm} \\
1.51 d^{-0.157} & 51<d \leq 254 \mathrm{~mm}\end{cases}
\end{aligned}
$$

Where $d_{e}$ is effective diameter and $d$ is the diameter of the rod. The load types acting on the joint part (upper leg) are axial and bending load. $k_{c}$ value for bending is 1 , while for axial is 0.85 . Therefore, a lower value of load modification factor $\left(k_{c}\right)$ was chosen which is 0.85 to make it safer. By considering the operating temperature is more than $20^{\circ} \mathrm{C}$, thus the temperature modification factor $\left(k_{d}\right)$ is 1.01 . The reliability factor $\left(k_{e}\right)$ is assumed to be $50 \%$ reliability so that the reliability factor value is 1 . The miscellaneous effect modification factor $\left(k_{f}\right)$ is 1 with the assumption that there are no other factors. 
- Endurance limit $\left(S^{\prime}{ }_{e}\right)$

The get the value of endurance limit $\left(S_{e}\right)$ of the material, the estimated endurance limit $\left(S^{\prime}{ }_{e}\right)$ need to be calculated first as follows.

$S^{\prime}{ }_{e}=\left\{\begin{array}{cl}0.5 S_{u t} & S_{u t} \leq 200 \mathrm{kpsi}(1400 \mathrm{MPa}) \\ 100 \mathrm{kpsi} & S_{u t}>200 \mathrm{kpsi} \\ 700 \mathrm{MPa} & S_{u t}>1400 \mathrm{MPa}\end{array}\right.$

Referring to the Table 1, the $S_{u t}$ of carbon steel AISI 1018 is $440 \mathrm{MPa}$. Thus $S^{\prime}{ }_{e}$ can be calculated as follows.

$S^{\prime}{ }_{e}=0.5 S_{u t}$

After getting the Marin Factor and $S_{e}^{\prime}, S_{e}$ can be calculated as follows,

$S_{e}=k_{a} k_{b} k_{c} k_{d} k_{e} k_{f} S^{\prime}{ }_{e}$

- The fatigue strength fraction $(f), a \& b$

From the $f-S_{u t}$ graph, the ultimate strength $440 \mathrm{MPa}$ is off the graph, so the value of $f$ is 0.98 .

$a=\frac{\left(f \cdot S_{u t}\right)^{2}}{S_{e}}$

$b=-\frac{1}{3} \log \left(\frac{f x S_{u t}}{S_{e}}\right)$

where $a, b$, and $f$ are determined constant.

- Finding $\sigma_{m}$ and $\sigma_{a}$

Fluctuating loads is range from $98.1-294.3 \mathrm{~N}$, so $M$ will range from $16-35.7 \mathrm{Nm}(\mathrm{CCW})$. It is found that $\sigma_{\min }=62.88 \mathrm{MPa}$ and $\sigma_{\max }=138.64 \mathrm{MPa}$. Since $q$ $=0$ and $k_{f}=1$, thus,

$\sigma_{m}=k_{f} \frac{\sigma_{\max }+\sigma_{\min }}{2}$

$\sigma_{a}=k_{f}\left|\frac{\sigma_{\max }-\sigma_{\min }}{2}\right|$

where $\sigma_{m}$ is the maximum stress and $\sigma_{a}$ is the alternating stress.
- Finding reverse stress based on Modified Goodman and cycle prediction

Using Equation (28), the fatigue safety factor of the child seat design for the front position was found to be 2.26 .

$$
n_{f}=\frac{1}{\frac{\sigma_{a}}{s_{e}}+\frac{\sigma_{m}}{s_{u t}}}
$$

\subsection{Mechanical strength calculation for the back-position}

On the back position, the seat will be installed to two symmetric support links on the left and right sides. Figure 11 shows the left support link. The support links are made from Steel AISI 1045 with the surface finished off cold drawn. The mechanical properties of the material are shown in Table 3. Because there are two symmetric support links, the force exerted by each link is equal to half of the total force, which is equal to 196.2 N. The Shear Force Diagram (SFD) and the Bending Moment Diagram (BMD) are shown in Table 4.

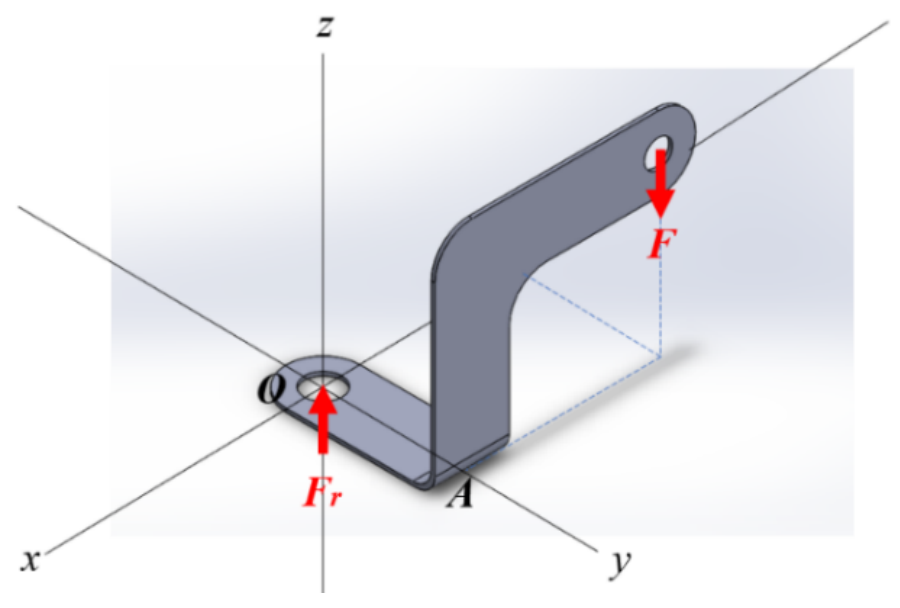

Figure 11 The left side support link.

Table 3 Mechanical properties of steel AISI 1045.

\begin{tabular}{lcc}
\hline \multicolumn{1}{c}{ Property } & Value & Units \\
\hline Elastic Modulus & $2.05 \times 10^{11}$ & $\mathrm{~N} / \mathrm{m}^{2}$ \\
Shear Modulus & $8 \times 10^{10}$ & $\mathrm{~N} / \mathrm{m}^{2}$ \\
Mass Density & 7850 & $\mathrm{~kg} / \mathrm{m}^{3}$ \\
Tensile Strength & $6.25 \times 10^{8}$ & $\mathrm{~N} / \mathrm{m}^{2}$ \\
Yield Strength & $5.3 \times 10^{8}$ & $\mathrm{~N} / \mathrm{m}^{2}$ \\
\hline Source: Solidworks Library &
\end{tabular}


Table 4 Shear force diagram (SFD) and the bending moment diagram (BMD).

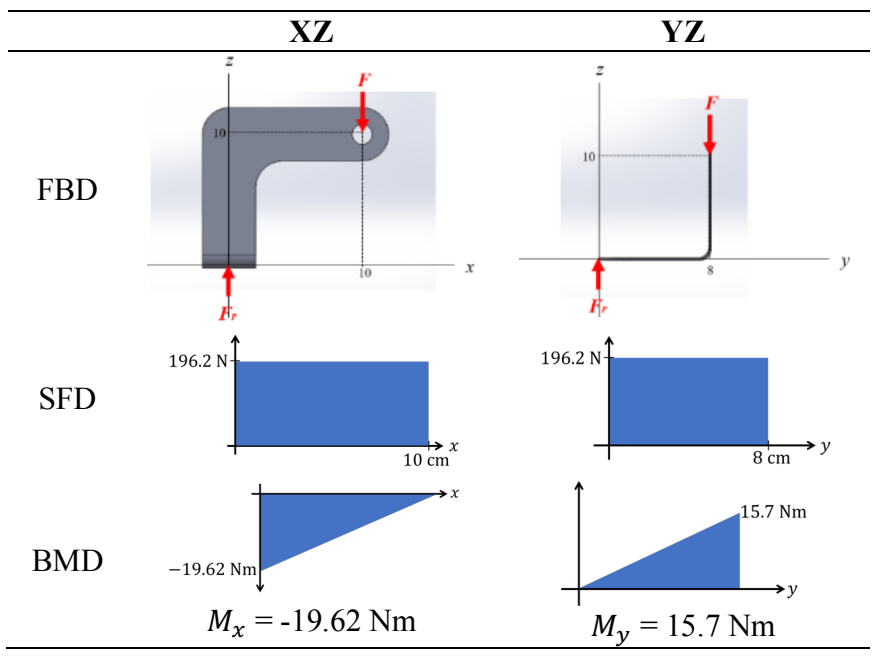

\section{Finding the stress on $y$-direction}

Figure 12 shows the supporting part in the Z-Y plane. $I_{I}$ and $I_{I I}$ are calculated as follows.

$$
I=\frac{1}{12} b h^{3}+A d^{2}
$$

$I_{y}$ which is the total moment of inertia were found to be equal to $1.01 \cdot 10^{-8} \mathrm{~m}^{4}$. Furthermore, the stress in the $\mathrm{Y}$ direction $\left(\sigma_{y}\right)$ was then calculated as follows.

$$
\sigma_{y}=\frac{M_{y} c}{I_{y}}=155.34 \mathrm{MPa}
$$

Where $M_{y}$ is the moment, $I_{y}$ is the $y$ inertia, $c$ is the distance from the center of the cross-section to the surface.
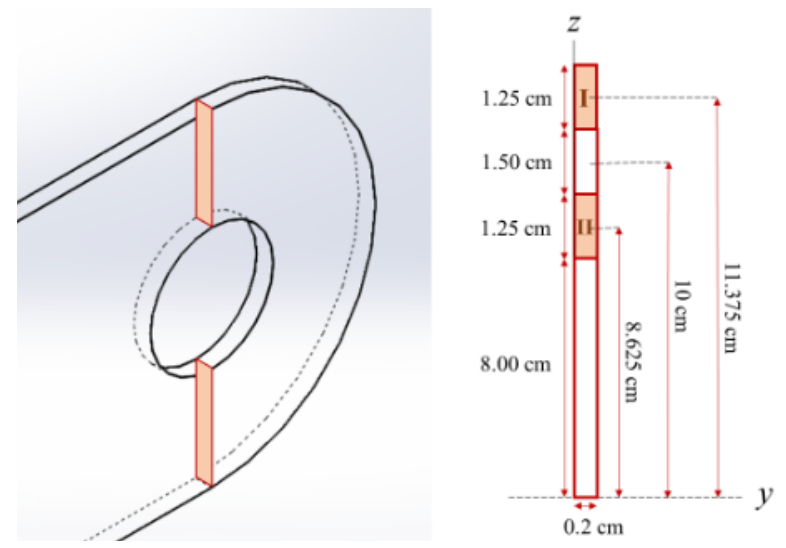

Figure 12 Supporting part in Z-Y plane view.

\section{Finding the stress on $x$-direction}

To simplify the calculation, the authors assume that the support link shape does not have the fillets, as shown in Figure 13. Using Equation (29), $I_{I I}$ and $I_{I I I}$ were found and the total inertia, $I_{x}$, is equal to $1.04 \cdot 10^{-5} \mathrm{~m}^{4}$. The normal stress was then calculated by using Equation (30) and found to be equal to $188.5 \mathrm{kPa}$.

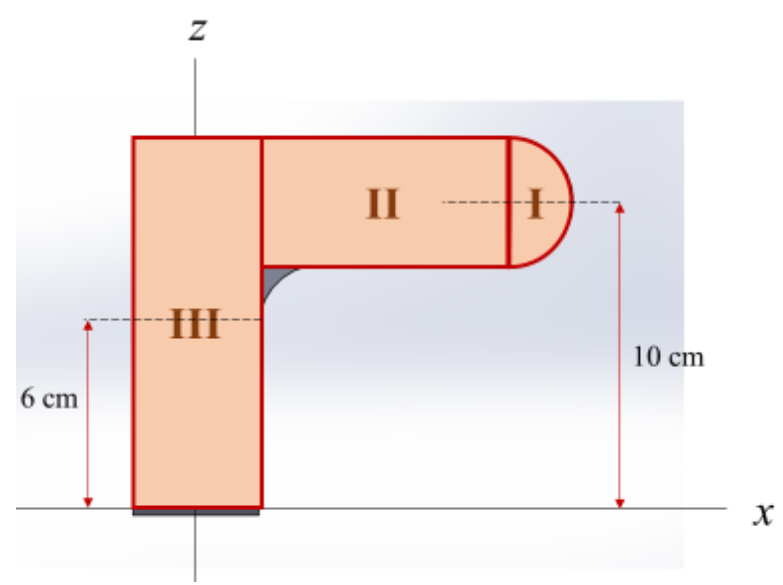

Figure 13 Supporting part shape in Z-X plane view.

$$
\bar{Z}=\frac{\sum A \bar{z}}{\sum A}=7.77 \mathrm{~cm}
$$

$I_{I}$ is then calculated as follows.

$$
I=\frac{1}{8} \pi r^{4}+A d^{2}
$$

\section{Finding the shear stress}

Figure 14 shows the shear stress direction on the supporting part member. The radius of the bolt is 0.75 $\mathrm{cm}$, thus

$$
\tau=\frac{F}{A}=1.11 \mathrm{MPa}
$$

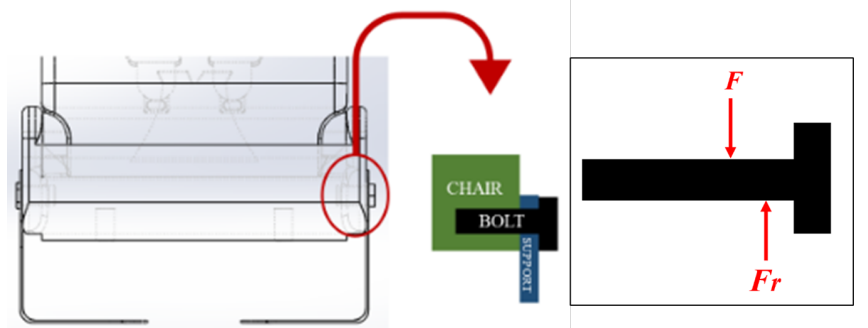

Figure 14 Shear stress direction on the supporting part member.

The principal stress is calculated as follows.

$$
\sigma_{\max , \min }=\frac{\sigma_{x}+\sigma_{y}}{2} \pm \sqrt{\left(\frac{\sigma_{x}-\sigma_{y}}{2}\right)^{2}+\tau^{2}}
$$

The stress maximum is found to be $155.35 \mathrm{MPa}$ and the stress minimum is $180.55 \mathrm{kPa}$. Then, the safety factor 
can be obtained by using the value of principal stress as follows.

$$
n=\frac{S y}{\sigma_{\max }}=3.41
$$

\section{Fatigue analysis of back position}

Fatigue analysis was used to predict the fatigue life of the frame. The first step was calculating the Marin Factor. The material used was Steel AISI 1045 with the surface finish off cold drawn, which resulted in a surface modification factor $\left(k_{a}\right)$ is equal to 0.82 . Second, the cross-section of this linkage has the dimensions $4 \mathrm{~cm}$ in length and $0.2 \mathrm{~cm}$ in width. The effective diameter is calculated to be $7.23 \mathrm{~mm}[12]$. This diameter was used to calculate the size modification factor by using Equation (20) and the result is $k_{b}$ equal to 1. Third, the linkage was given the bending load, where the loading factor for bending was found to be 1 . Fourth by using the same assumption with the frontseat-frame, at temperature $50^{\circ} \mathrm{C}$, the value of $k_{d}$ will be 1.01 .

By using Equation (22), the endurance limit or $S_{e}{ }^{\prime}$ is found to be equal to $312.5 \mathrm{MPa}$. Using Equation (23), the actual endurance limit or $S_{e}$ found to be equal to 259.39 MPa. After getting the value of the Marin factors, $n_{f}$ can be obtained by using Modified Godman Criteria. Using Equations (26) and (27), the alternating and maximum stress was found to be $77583.73 \mathrm{kPa}$ and $77764.28 \mathrm{kPa}$, respectively. The safety factor $\left(n_{f}\right)$ was calculated by using Equation (28) and the result is 2.36. Therefore, infinite life was predicted.

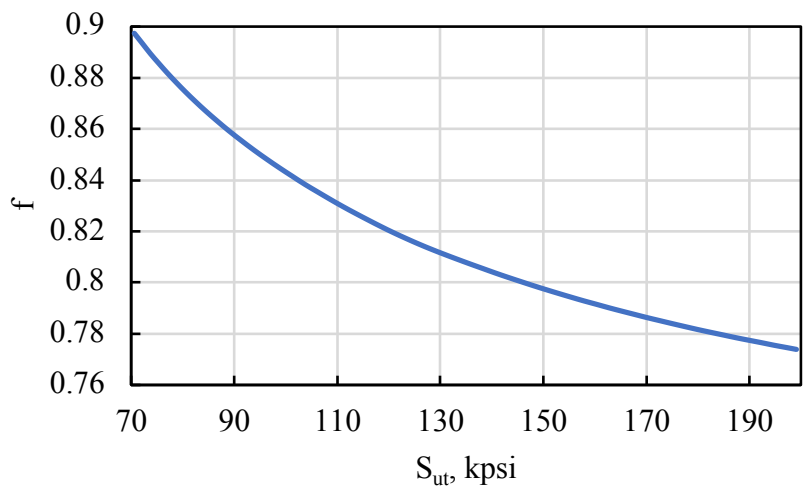

Figure 15 Fatigue strength fraction, $f$, of $S_{u t}$ at $10^{3}$ cycles for $S_{e}=S_{e}^{\prime}=0.5 S_{u t}$ at $10^{6}$ cycles [12].

To obtain the number of cycles, the authors used the graph in Figure 15, for $S_{u t}$ of $625 \mathrm{MPa}(90.65 \mathrm{kpsi})$, the value of $\mathrm{f}$ is around 0.85. Using Equation (24) and (25), the value of $a$ and $b$ are $1082.93 \mathrm{MPa}$ and -0.1 , respectively.

$$
N=\left(\frac{\sigma_{r e v}}{a}\right)^{\frac{1}{b}}
$$

Finally, by using Equation (36), the cycle was predicted to be $3.23 \times 10^{10}$ cycles before it fails under fatigue. The number of cycles is higher than $10^{6}$, which is categorized as a very high cycle or infinite life. Therefore, it can be concluded that the support links for the back position are safe.

\section{Conclusion}

A portable and robust design of a child seat for a motorcycle which can be installed in the front and back sides, are introduced in this work. The proposed design has a mass of 0.6 kilograms for the back position and 3 kilograms for the front position. By these values, the child seat design is quite light compared to the maximum load that can be carried by motorcycle, i.e., 120-150 kilograms. Based on the strength analyses under static and fatigue load, the front and back positions show an infinite service life indicated by the fatigue safety factor of 2.26 and 2.36, respectively. Therefore, putting a child seat on the back of the motorcycle is recommended if the user wants the product to be more durable. However, they also can choose to place it at the front so that watching the children while reading the motorcycle is easier. In this case, careful consideration of the traffic rule in Indonesia is needed. For further work, the material used, its shape and dimension, the fabrication means need to be carefully optimized to reach a good balance in terms of cost, weight, reliability, usability, durability, and other design considerations. In addition, the proposed design is expected to be considered as one idea for an innovative product in the transportation field.

\section{References}

[1] S. Pance, D. Piskac, A. Bures, A. Voldrich, M. Kovac, and B. A. Budiman, "Evaluation of Motorcycle Energy Consumption in Urban Traffic," Int. J. Sustain. Transp. Technol., vol. 2, no. 1, pp. 27-31, 2019.

[2] Central Bureau of Statistics, "Development of Number of Motorized Vehicles by Type (Unit), 2017-2019." [Online]. Available:

https://www.bps.go.id/indicator/17/57/1/perkembanganjumlah-kendaraan-bermotor-menurut-jenis.html. [Accessed: 21-Aug-2021].

[3] Central Bureau of Statistics, "Number of Accidents, Death, Serious Injury, Minor Injury, and Material Losses 20172019." [Online]. Available: https://www.bps.go.id/indicator/17/513/1/jumlahkecelakaan-korban-mati-luka-berat-luka-ringan-dankerugian-materi.html. [Accessed: 21-Aug-2021].

[4] E. Yanwardhana, "The Accident Rate in Indonesia Soars, the Most Cases of Blong Brakes," 2021. [Online]. Available: https://www.cnbcindonesia.com/news/20210421084324-4239452/tingkat-kecelakaan-di-ri-melesat-terbanyak-kasusrem-blong. [Accessed: 21-Aug-2021]. 
[5] S. Zulaikah, W. H. Rahmanda, and F. Triawan, "Foldable front child-seat design for scooter motorcycle: Strength analysis under static and dynamic loading," Int. J. Sustain. Transp. Technol., vol. 3, no. 2, pp. 37-44, 2020.

[6] N. F. Paiman, A. Shabadin, A. H. Ariffin, S. M. Syazwan, and H. Azhar, "Child motorcycle pillion rider anthropometric measurement," in Applied Mechanics and Materials, 2014, vol. 663, pp. 557-561.

[7] K. Kanawipawut, J. Carmai, and S. Koetniyom, "Development of motorcycle child seat to mitigate injury during motorcycle crash," 2018.

[8] I. L. Al Qushai, A. Sholeh, W. N. Budiarta, and F. Triawan, "Motorcycle Child Seat for Child with Special needs: Its Design Process and Problem-based Learning," Indones. J. Community Spec. Needs Educ., vol. 1, no. 2, pp. 93-102.

[9] D. F. Huelke, "An overview of anatomical considerations of infants and children in the adult world of automobile safety design," in Annual Proceedings/Association for the
Advancement of Automotive Medicine, 1998, vol. 42, p. 93.

[10] K. Dwijayanti, M. C. Zulfa, and D. Rohmawati, "Perancangan Kursi Bonceng Anak Usia 1-3 Tahun untuk Motor Matic dengan Metode QFD dan Antropometri," $J$. DISPROTEK, vol. 9, no. 2, pp. 110-126, 2018.

[11] AZO Materials, “AISI 1018 Mild/Low Carbon Steel,” 2019. [Online].

Available: https://www.azom.com/article.aspx?ArticleID=6115.

[Accessed: 21-Aug-2021].

[12] R. G. Budynas and J. K. Nisbett, Shigley's mechanical engineering design. Mc Graw Hill, 2015.

[13] M. Arnani, "Hot Temperatures in the Territory of Indonesia, What Causes it and Until When?," 2021. [Online]. Available:

https://www.kompas.com/tren/read/2021/10/18/160000665 /suhu-panas-di-wilayah-indonesia-apa-penyebabnya-dansampai-kapan-?page=all. [Accessed: 19-Oct-2021]. 